\title{
Incarcerated ovarian hernia in the umbilicus
}

\author{
S. E. F. Edmonds • K. Allenby
}

Received: 29 September 2006 / Accepted: 5 April 2007 / Published online: 11 May 2007

(C) Springer-Verlag 2007

\begin{abstract}
This case regards a morbidly obese lady presenting with a massive ovarian tumour herniating through the umbilicus. Six months previously she had suffered from a life-threatening pulmonary embolus requiring supportive ventilation at the same hospital. Herniation of the ovary directly into the umbilicus is very rare and here we provide pictoral evidence and advice regarding the management of this patient.
\end{abstract}

Keywords Incarcerated ovary $\cdot$ Umbilical $\cdot$ Hernia

\section{Case report}

A 55-year-old post-menopausal Maori lady was admitted under the surgeons with a 7-day history of tenderness and redness in her umbilicus, with worsening abdominal pain, lethargy and urine retention. Six months previously, she had been on the intensive care unit at the same hospital with nearfatal massive pulmonary and right ventricular emboli, which were treated with streptokinase infusion and significant respiratory support. Abdominal examination at the time was reported as "nothing abnormal".

S. E. F. Edmonds

Benenden Hospital,

Benenden, Kent, UK

K. Allenby

Middlemore Hospital,

Auckland, New Zealand

S. E. F. Edmonds $(\bowtie)$

Cranbrook Road,

Kent TN17 4AX, UK

e-mail: sedmonds@benenden.org.uk
She was referred to the gynaecologists following abdominal ultrasound and CT scanning. Abdominal examination revealed a morbidly obese woman of $158 \mathrm{Kg}$ (Basal Metabolic Index (BMI) of 45) (Fig. 1), with massive abdominal distension secondary to a solid mass thought to be arising from an ovary. There appeared to be an incarcerated herniation of the mass through the umbilicus, causing a localised tender spot at the base of the umbilicus. The patient was unable to stand unaided, and complained that her abdominal girth had been increasing for 2 years, despite advice by previous medical staff to lose weight to reduce her size.

Tumour markers were elevated, with a CA125 of $224 \mathrm{kU} / \mathrm{l}$, haemoglobin of $7.03 \mathrm{mmol} / \mathrm{l}$ but otherwise normal renal and liver function tests. Chest X-ray did not reveal any extraperitoneal masses, and abdominal $\mathrm{CT}$ scan showed a $41 \mathrm{~cm} \times 33 \mathrm{~cm}$ mass, consisting of mainly fat but also some calcified areas and septae.

Following anaesthetic review and an informed discussion regarding the significant risks associated with surgery, the patient was booked for midline laparotomy. The midline incision site was marked preoperatively (Fig. 1).

At operation, in a left lateral tilt, entry into the abdomen was difficult due to a loss of the natural tissue plains secondary to inflammation and adhesions between the mass and the anterior abdominal wall. A lobule of tumour was found to be herniating through the umbilicus, causing a true umbilical hernia (Fig. 2). Following extensive dissection, a right oophorectomy was performed. The entire umbilicus was removed and the rectus sheath resutured. The uterus and remaining ovary were left in situ to minimise on table operative time and the risks of haemorrhage. Thromboprophylaxis was continued with high-dose subcutaneous low molecular weight heparin until the day of discharge, 7 days post-operatively. 
Fig. 1 Pre-operative appearance

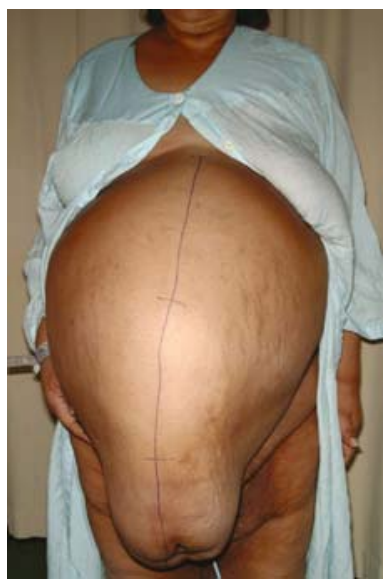

The patient made a good recovery and was able to walk into clinic unaided when seen at 6 weeks, having lost $27 \mathrm{~kg}$ (11.5 kg due to tumour). Histology confirmed a benign cystic teratoma (dermoid cyst) of the ovary with no malignant components.

\section{Discussion}

There are numerous case reports of herniation of the ovaries through the inguinal canal (most commonly in newborn

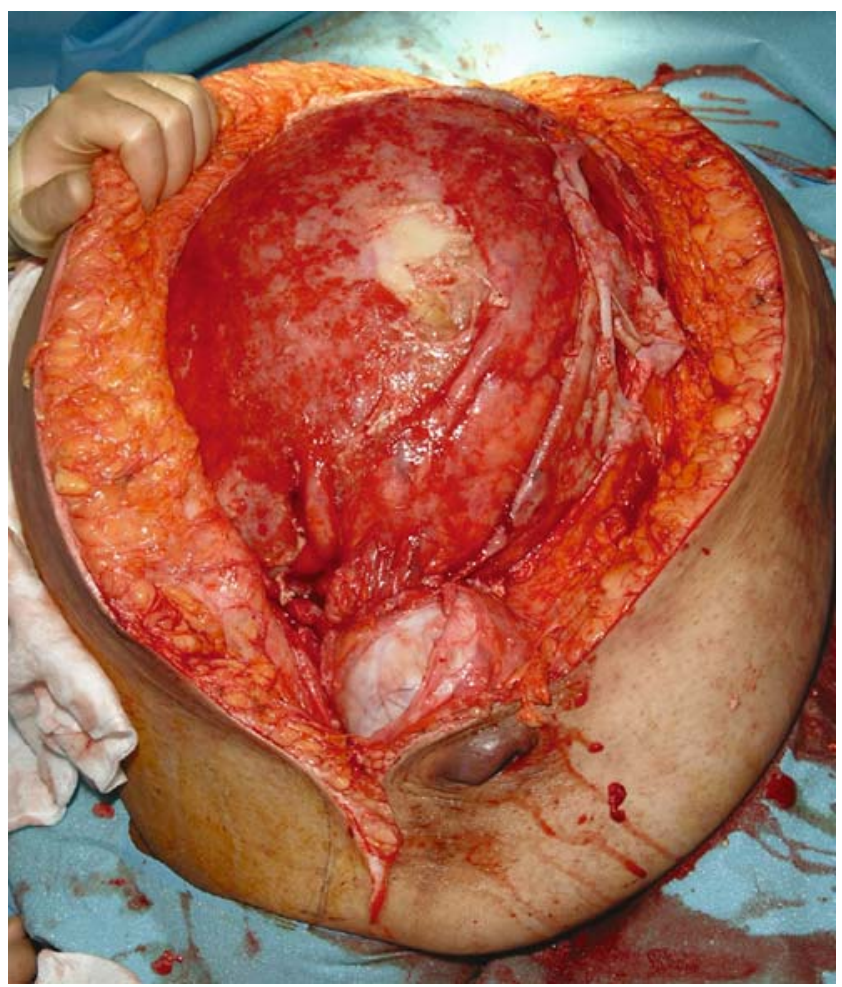

Fig. 2 Tumour nodule into umbilicus girls [1], but also in adults [2, 3]), the obturator foramen [4] or the femoral canal [5]. Malignant ovarian tumours may present with a co-existent metastasis in the groin [6], or in the umbilicus [7]. There has only been one previous report in the literature of an ovarian tumour herniating into the umbilicus [8], but this is the first report of an incarcerated umbilical hernia due to a massive dermoid cyst. As a pelvic organ, the ovary does not enter the abdominal cavity unless enlarged. In this case, the large nodule of tumour extending from the greater portion of the mass had become incarcerated into the base of the umbilicus, creating a hernial sac. This led to the acute presentation.

Dermoid cysts are usually benign, and may be bilateral in up to $10 \%$ of cases. Less than $2 \%$ may contain a malignant component, usually a squamous carcinoma. This is more common in women over the age of 40 . The majority of benign dermoid cysts are asymptomatic, but they may undergo torsion. More rare is spontaneous rupture, which causes a chemical peritonitis, or - if slowly as is likely in this case - a chronic granulomatous peritonitis leading to adhesions and chronic pain.

Immobility due to morbid obesity, the hypercoagulable state from an inflammatory mass, and direct compression of the inferior vena cava by the mass causing venous stasis all increase the risks of thrombosis.

This case report is a reminder for all medical staff to consider investigation of the abdominal cavity with ultrasound following pulmonary embolism, particularly in obese women.

\section{References}

1. Fowler CL (2005) Sliding indirect hernia containing both ovaries. J Paediatr Surg 40(9):e13-e14

2. Golash V, Cummins RS (2005) Ovulating ovary in an inguinal hernia. Surgeon 3(1):48

3. Ray S, Som SC, Adedji EA, Williams GT, Ferguson A (2003) Ovarian and tubal inguinal hernia - an unusual presentation. $\mathrm{J}$ Obstet Gynaecol 23(3):323-324

4. Yoshida S, Shidoh M, Shibuya H, Nishida R (2002) Ovarian obturator hernia. Lancet 360(9334):715

5. Almond TH (1963) Inclusion of the ovary in a femoral hernia. Can Med Assoc J 89:1153

6. Matthews SJ, McClelland HR (1998) Saved by a hernia: an unusual presentation of ovarian cancer. Int J Clin Pract 52(2):127-128

7. Leroy C, Gontier MF, Gontier F, Minh HN, Smadja A (1992) Malignant dermoid cyst of the ovary with double tumor cell population, revealed by an umbilical metastasis. Ann Pathol 12 (3): $178-182$

8. Wolfson N, Graves K, Pastorek JG 2nd, Suleman M (1991) Benign cystic teratoma manifested as an umbilical hernia. South Med J 84 (3):405 